weiter erörtert werben fönnen, - zurąeit nicht möglich ift. Nach wie bor

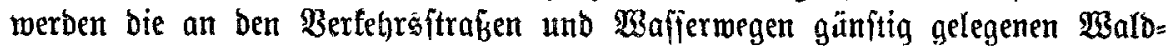

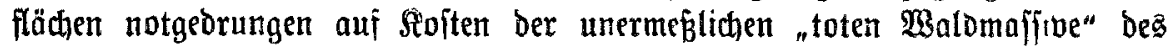

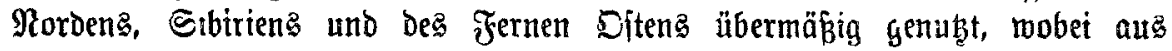
Slapitalmangel für eine befriebigende Berjüngung nicht gejorgt merden fann. (5) ift gar nicht abzufeben, welche Folgen bie weitere Entmalbung Der bichter be= völterten und ohnehin idwach brwaldeten (Segenden nach fich ziehen werben.

Bom Stanopunft eines Deuticten Forfipolitifers fino bie fomjetruffictien Berhältmifje ber Forjtmirtichajt und des \$olzmarttes gerabezu tatajtrophal.

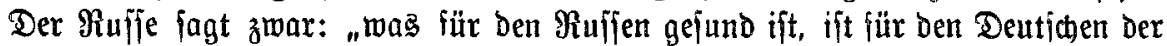
Tod", und hat bamit in mancher Beziebung recht. Tatiache ift, dấ für bie Beurteilung rufficher Bectältnrffe cin ganz anderex Mioß̧itab angemendet merden muß̃ als für mejteuropäijche. Der $\mathfrak{B e f t e u r o p a ̈ e r ~ l a n n ~ f i ̈ h ~ u ̈ b e r b a u p t ~}$ feine Borftellung machen, unter welch idhwierigen Berbältniffen, herborgeruien

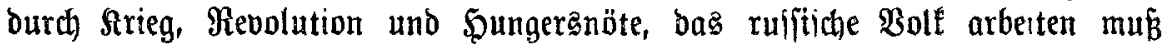
und wie langfam fith ber Miederaufbau bieles Bufunftelandes vollzieht.

Bon Den in Den früheren amilichen Mitteilungen und in ber "Foritpolitif ber Somjets" (Mostau 1925, Berlag "Nowaja Deremrja“) vielfach betonten

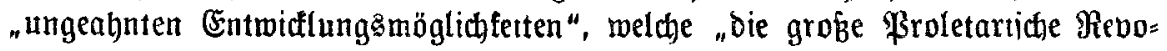
lution“ ipeztell ber Forftwirtichaft Durch bie Nationalifierung Der $\mathfrak{B a a l b e r}$ in

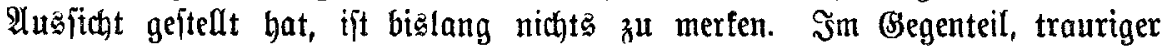

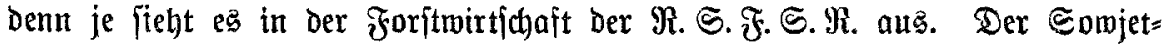
regierung fann ber $\mathfrak{B}$ orwurf nicht erjpart bleiben, eine foritltche Raubwittidjaft geführt zu haben, Die fich zmar Durch bie außerordentlichen Berbältnijfe ent=

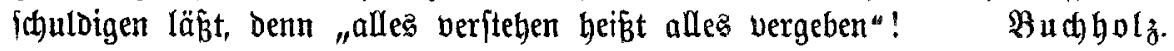

\title{
IV. Kurje Rachrichten.
}

\section{Arbeitsgemeinfhaft für Juwachsförderung.}

Steigerung ber Dolyergeugung nad Maffe uni Mert ift bringlidfite Begenmartionfgabe

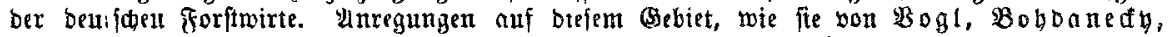

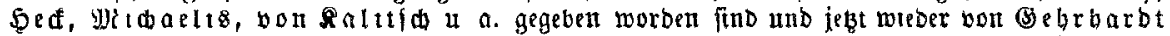

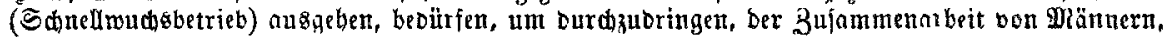

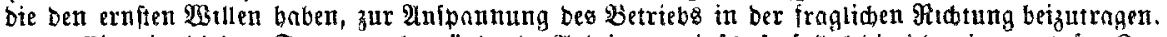

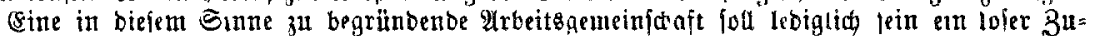

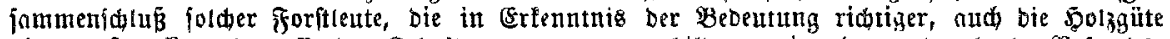

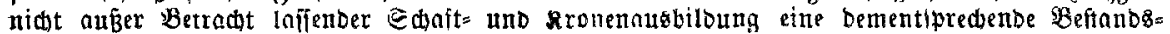
erkiebung irgend melder form beretts getrieben baben ober in ibrem 26 irfungstrets anmenden

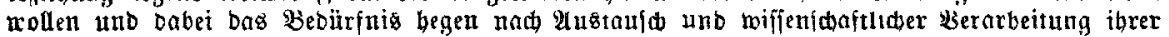
Erfabrungen. Fer hiernach zit bilbende sreis foll jeinen Plutelpunft uno feine Sammelftelle

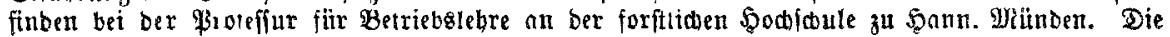

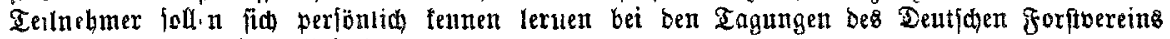
unto curd gegenfertigen Beiuch.

Die Unterzeidneten bitten Berufsgenoffen, bie gewillt finb, an bieler „Mrbeit gemrinidaft

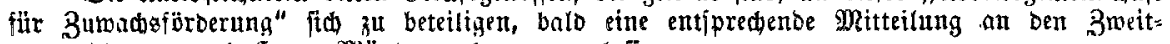

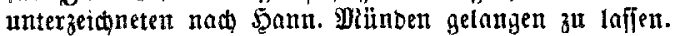

Dengler. Bebrbarbt. Febel. Roḱmäbler. 5. Beber. Bentgraf. 